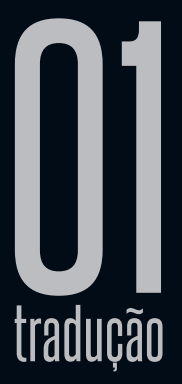

\title{
O FANTÁSTICO NO CINEMA. SONHOS E MEDOS DO TERCEIRO MILÊNIO ${ }^{1}$
}

Irène Bessière ${ }^{2}$

Antes de definir o cinema fantástico dos últimos dez anos ${ }^{3}$, suas principais evoluções, suas transformações e de traçar um panorama sintético, quero fazer duas ou três observações preliminares sobre meus trabalhos acerca do gênero fantástico na literatura e sobre o fantástico no cinema. Sei que, para alguns de vocês, estou mais ligada à literatura do que ao cinema, o que me leva a explicar minha

1 "Lo fantástico en el cine. Sueños y miedos del tercer milenio", texto traduzido do francês por Marcela Santero e originalmente publicado em Fantasmas, sueños y utopías en literatura, cine y artes plásticas, sob a organização de Cristina Elgue-Martini e Luigi Volta (Córdoba: El Copista/ Facultad de Lenguas - UNC, 2009. p.115-132.), corresponde à conferência proferida por Irène Bessière, em 2 de agosto de 2005, na Aliança Francesa, em Córdoba, Argentina, antecedendo ao Seminário que deu título ao livro, promovido pelo Centro de Investigaciones en Literatura y Cultura de la Facultad de Lenguas de la Universidad Nacional de Córdoba, realizado em 28 e 29 de setembro daquele mesmo ano. Esta publicação, cuja tradução do espanhol para o português foi feita por Ana Cristina dos Santos e Flavio García, está devidamente autorizada pela autora.

Os tradutores agradecem a importantíssima colaboração de Cláudio Zanini, cinéfilo assumido e pesquisador dessas vertentes do cinema abordadas por Irène Bessière, que fez uma criteriosa revisão desta tradução, encontrando problemas já presentes no texto original em espanhol ou decorrentes de escolhas durante sua tradução para o português. 2 Irène Bessière é autora de Le récit fantastique: La poétique de l'incertain (Paris: Larousse Université, 1974), obra vista pela crítica da ficção fantástica como contraponto à Introduction à la littérature fantastique (Paris: Editions du Seuil, 1970), de Tzvetan Todorov. 3 Considerando-se o ano de apresentação da conferência, 2005, os últimos dez anos abrangem um recorte cronológico que recua até 1995. 
trajetória pessoal. Depois, desejo fazer duas ou três pequenas observações sobre os diferentes problemas específicos em torno da representação do fantástico no cinema, que parecem ser muito diferentes dos delineados em uma narrativa fantástica literária.

Hoje, a literatura fantástica me parece um tanto distante, e sou, certamente, responsável por isso, já que fui eu quem se afastou dela, e, ao retomar os grandes textos fantásticos literários, sejam clássicos ou contemporâneos, tenho enfrentado a problemática de sua adaptação para o cinema. Paulatinamente, venho me apaixonando pelo cinema, sobre o qual trabalho, de maneira exclusiva, desde aproximadamente quinze anos, o que não exclui o fantástico de maneira alguma.

Há quinze anos, meus estudos profissionais e pessoais estão estreitamente vinculados a pesquisas cinematográficas em duas diferentes instituições parisienses: I'Institut National de l'Histoire de l'Art (Inha) e a Fundation Maison des Sciences de I'Homme (FMSH) - onde concebi, criei e organizei dois programas de pesquisa cinematográfica: um sobre as relações entre a história da arte do cinema através da criação do gosto no campo cinematográfico (Inha), outro sobre a criação no exílio através da emigração e do exílio de cineastas europeus nos Estados Unidos (FMSH).

As outras observações que eu gostaria de fazer rapidamente giram em torno de dois problemas específicos que o fantástico apresenta no cinema, no que tange à representação e à narração, problemas bem diferentes dos que pode apresentar um texto fantástico na literatura.

A primeira e mais evidente das diferenças é aquela em que todos pensamos: o cinema tem por objetivo mostrar e, portanto, 
obriga a aceitar, de início, o que mostra ao espectador. Mas como conseguir que os espectadores adiram a um mundo totalmente imaginário, ainda que seja uma mistura de real e de fantasmagórico, ou carregue ao mesmo tempo a marca do familiar e do estranho? Todos nós sabemos, porque os profissionais do cinema, os críticos, os historiadores, todos os especialistas do cinema têm repetido bastante, que se um espectador não penetra no universo do filme durante os cinco primeiros minutos, não penetrará jamais. É o que se conhece no meio cinematográfico por suspension of disbelief ${ }^{4}$, que no cinema fantástico adquire uma importância primordial. Poucos filmes conseguem provocar essa adesão imediata no espectador $\mathrm{e}$ fazê-lo percorrer o caminho do fantástico.

Por outro lado, mostrar as coisas, as situações sob uma luz demasiado intensa, poderia "matar" diretamente o fantástico, fazendo-o perder credibilidade e privando-o de seu poder evocador. Sugerir pode ser uma das formas de sua representação no cinema, pois lhe permite preservar seu mistério, seu enigma e, paralelamente, solicitar a imaginação do espectador, conservando o transcorrer onírico do fantástico.

Há um diretor que compreendeu isso muito bem. Trata-se de Jacques Tourneur, como se percebe especialmente no filme Cat people [Sangue de pantera] $]^{5}$, no qual conta a história de uma jovem que, sob a influência de certas emoções, transforma-se em pantera. No filme de Tourneur, jamais presenciaremos a transformação da

4 Essa expressão é atribuída ao poeta inglês Samuel T. Coleridge no século XIX e vem sendo empregada em estudos sobre ficção, independentemente de se tratar de literatura, teatro, cinema, televisão etc.

5 Sempre que os filmes referidos pela autora tiverem sido lançados no Brasil, reproduziremos entre colchetes, quando de sua primeira referência no texto, o título que lhe foi atribuído na versão brasileira. 
jovem em pantera, tampouco veremos a pantera, mas veremos, na que se considera uma das cenas mais aterrorizantes do cinema fantástico, a sombra da pantera desenhada em uma parede como sombra chinesa, o que constitui uma resposta estética absolutamente pertinente para o problema da representação do fantástico no cinema.

Para concluir essas observações sobre a representação do fantástico no cinema, citarei, como exemplo, um grande autor do gênero fantástico, bastante conhecido, mas muito pouco adaptado ao cinema: Howard Phillips Lovecraft. Por quê? Durante suas descrições de situações horrendas e de personagens monstruosas, há sempre um momento em que Lovecraft detém sua narração e diz: "É indizível". Como representar o indizível no cinema? O que significa, inclusive, a noção de indizível no cinema? Aproxima-se da noção de invisível, de irrepresentável, de imostrável? Sendo assim, é absolutamente oposto à essência mesma do cinema, uma vez que a essência do cinema é precisamente mostrar. Os cineastas têm procurado e proposto diferentes soluções para esse problema. Darei somente um exemplo: a trilha sonora substitui a imagem e o faz, em parte, para criar a atmosfera fantástica e o medo: é necessário observar que, no cinema fantástico, a trilha sonora tem uma enorme importância. Desempenha um papel decisivo no cinema em geral, porém, muito especial no cinema fantástico. A imagem, na tela, permanece relativamente realista ou neutra, mas é o som, a trilha sonora, o que vai gerar a angústia, criar a atmosfera e, finalmente, provocar medo.

Até aqui, algumas observações muito rapidamente delineadas com o objetivo de apontar algumas pistas de reflexão sobre o "por 
quê" do cinema fantástico. Traçarei, em seguida, um sintético panorama do cinema fantástico nos últimos dez anos.

Na última década, a produção do cinema fantástico foi particularmente rica e variada, mesclando os filmes de concepção mais clássica com moderníssimos efeitos especiais. Tal é o caso de The Haunting [A casa amaldiçoada] de Jan de Bont ou ainda The Mummy [A múmia] de Stephen Sommers, com aqueles que renovam o gênero, seja por sua temática, como The Sixth Sense [O sexto sentido] de M. Night Shyamalan, ou mesmo Cube [Cubo] de Vincenzo Natali, seja pelo olhar dirigido ao fantástico, como Scream [Pânico] de Wes Craven, para citar apenas esses filmes.

De fato, a partir de Scream, que é de 1996, pode-se apreciar um verdadeiro renascimento do cinema fantástico e do cinema de terror. Esse filme soube reunir, de maneira inteligente, com seu bom ritmo e sua boa direção, a intriga de um thriller com assassinatos em série e uma reflexão sobre o gênero de terror baseada em uma coleção de referências cinéfilas tratadas com humor e, às vezes, próximas da paródia. Numerosos longa-metragens, em que se observam novas tendências que poderiam levar a um tipo muito diferente de fantástico, seguiram-se a esse filme. É evidente que o final do segundo milênio e o começo do terceiro, que eu chamaria de período dobradiça, representam, para o cinema fantástico, um período de transição extremamente importante.

Poderíamos, para simplificar a análise do cinema fantástico deste fim e início de milênio, ressaltar três tendências essenciais. A primeira tendência desse cinema fantástico retoma as figuras perfeitamente conhecidas, para não dizer convencionais, do 
filme fantástico, mas apresenta igualmente uma reflexão sobre o gênero em si mesmo. Trata-se de filmes que renovam o gênero graças a sua estratégia original de privilegiar o nó central de toda narrativa fantástico: enigma, mistério, desconhecido e medo. Sob esse ponto de vista, três filmes são particularmente interessantes: Scream, já sinteticamente apresentado, e dois filmes norteamericanos The Sixth Sense de M. Night Shyamalan e The Blair Witch Project [A bruxa de Blair], este último realizado por dois jovens diretores de 25 e 28 anos, Daniel Myrick e Eduardo Sánchez. É evidente que outros filmes poderiam ser inseridos nessa nova tendência do cinema fantástico, como Los Otros [Os Outros] do espanhol Alejandro Amenábar, ou ainda os filmes japoneses Ringu [O chamado] ou Dark Water [Água negra].

Scream é realmente interessante, não porque conte a história de um serial killer, mas porque permite vários níveis de leitura. Trata-se de um thriller cuja intriga é bastante horrível, baseado no esquema bem conhecido de uma pequena cidade, na América do Norte confusa, povoada por adolescentes simpáticos e sedutores que serão assassinados uns depois dos outros. A originalidade desse filme depende dessas personagens aparentemente clássicas, mas que são, antes de tudo, cinéfilos aficionados pelos filmes de terror, para as quais tudo gira em torno desse tipo de filmes e que parecem ter perdido contato com sua própria realidade. Sua visão se satisfaz através dos lugares comuns dos filmes de terror, que conhecem de memória, e isso dá lugar, evidentemente, a uma exploração do gênero, mas também a um filme que oscila entre a realidade e a paródia, entre o riso e o medo, e que, além de sua intriga convencional, propõe uma híbrida composição de vida e 
cinema, invertendo todos os clichês do gênero, porque, como bem sabemos, a vida e o cinema são diferentes, e o cinema não é a vida. Chega-se, desse modo, ao essencial do filme: mostrar personagens que vão ao cinema, insistir sobre o conhecimento que essas personagens têm do cinema fantástico, e falar da relação entre o cinema e seu público.

Sob esse ponto de vista, uma cena final do filme é bastante representativa. Um dos adolescentes, sentado tranquilamente em um sofá, está vendo na televisão a primeira parte de Halloween, de John Carpenter, precisamente a cena em que a heroína é ameaçada com uma faca pelo assassino. Ele a está advertindo aos gritos, inutilmente, enquanto que, detrás dele, se vê o assassino de Scream, e ambos, a heroína de Halloween e o jovem de Scream, serão atacados simultaneamente pelo assassino de cada um dos filmes. Essa construção "em abismo", muito pouco frequente no cinema fantástico, essas idas e voltas entre paródia, seriedade e terror, essa aliança entre o medo e o riso garantem a consecução de um filme muito original e estimulante para o espectador.

Em The Sixth Sense, o tema se refere à ordem do paranormal e do sobrenatural, uma vez que trata de um menino de oito anos que vê os fantasmas de pessoas mortas, sendo tratado por um psicólogo infantil. Contrariamente aos filmes desse gênero, este não apresenta nenhuma pergunta, não dá nenhuma resposta, e se, apesar de tudo, o enigma está no coração do filme, não é o que se crê, e o final não explica por que esse menino sofre alucinações, nem se vê realmente as pessoas mortas. Tudo se centra em uma atmosfera de horror psicológico e em um sistema progressivo de revelações sobre as personagens principais, o psicólogo e o menino, cujos destinos são 
paralelos e cuja relação se aprofunda e enriquece passo a passo. 0 final é, na realidade, uma surpresa total, que leva a reconsiderar o filme sob um ponto de vista absolutamente diferente.

É necessário observar que se trata de uma tendência muito contemporânea do cinema em geral e não somente do fantástico: o final nega totalmente o que acaba de se ver e convida a uma segunda leitura e a uma segunda visão do filme, como, por exemplo, se dá no caso de um filme muito conhecido, The Usual Suspects [Os suspeitos]. Em The Sixth Sense, o fantástico é a oportunidade para uma medição lenta e profunda, frequentemente muito desoladora, sobre a vida e a morte e sobre a vida no além. Sem violência, sem efeitos especiais, sem um verdadeiro enigma, o filme conduz os espectadores a uma reflexão e a um mistério que ultrapassam as intrigas sobrenaturais conhecidas. Foi dito que The Sixth Sense pertencia à escola do que se chama, na linguagem cinematográfica, "less is more", ou seja, "menos é mais", já que não recorre aos efeitos especiais, ao gore ${ }^{6}$ e à violência sangrenta.

The Blair Witch Project vai além nessa via, apresentando-se como um documentário que foi encontrado depois do desaparecimento dos três jovens diretores que o realizaram. A grande originalidade desse filme reside precisamente nesse aspecto documental: filmado com a câmera ao ombro, seguindo as personagens por todos os lados, em seus mínimos gestos e ações e em seu pânico crescente quando se perdem no bosque procurando a bruxa do título. Aqui não há violência alguma, nenhum efeito especial, nada de sangue. Tudo é entregue à imaginação do espectador, e sempre se soube que o monstro mais temível não é aquele se pode ver, mas o que se imagina.

6 É um tipo de filme de terror que se centra no visceral e na violência gráfica extrema. 
Tudo parece ser verdade, e vemos esse pequeno grupo desintegrarse literalmente diante dos nossos olhos. Então, paulatinamente, vaise apagando a fronteira entre ficção e realidade. O filme parece ser muitíssimo mais real, visto que seus diretores tiveram a inteligência de criar, dois meses antes de sua estreia, uma página na internet que deu origem a uma verdadeira mitologia em torno do filme, apresentando sua história como verídica e documentada, dando, assim, origem à nova lenda. Trata-se de um caso único na história do cinema. Poderia ser comparado ao impacto produzido pela emissão radiofônica de Orson Welles, sobre a guerra dos mundos, que fez milhares de norte-americanos pegarem a estrada, convencidos de que os marcianos estavam chegando a Terra para exterminálos. O impacto devido à página na internet foi imenso e contribuiu notoriamente para o êxito do filme, inventando, ao mesmo tempo, um novo tipo de relação entre o cinema e a tecnologia moderna.

Nessa primeira tendência do novo cinema fantástico, não se pode deixar de falar de dois filmes que são extremamente diferentes, mas muito bem feitos: Los Otros [Os Outros], realizado nos Estados Unidos, com financiamento norte-americano, pelo diretor espanhol Alejandro Amenábar, e o filme japonês (a tradição do fantasma no cinema e na literatura se mantém muito viva no Japão) Ringu [O Chamado], bastante interessante.

Em síntese, Los Otros [Os Outros] é a história de uma mãe e seus dois filhos que vivem em um lugar absolutamente fechado, a tal ponto que nem a luz do dia pode sequer penetrar, visto que as crianças sofrem de uma doença que as impede de ver a luz, correndo, inclusive, o risco de morrerem caso isso acontecesse. 0 filme possui uma força onírica e uma intensidade extraordinária 
ao desenvolver-se em uma semibruma perpétua, criando uma atmosfera de estranheza permanente. O que faz esse filme ser ainda mais interessante é que a mãe e os dois filhos (o pai está na guerra, devendo tratar-se da Primeira Guerra Mundial) sentem continuamente medo nessa casa e estão convencidos de que está assombrada, e, à vezes, têm a impressão de entrever uma família cujo pequeno filho chora intensamente. Como The Sixth Sense, produz-se uma inversão no final do filme. De fato, os fantasmas são a mãe e seus filhos e as personagens reais são aquelas que tinham sido consideradas fantasmas durante todo o filme. Trata-se de um filme notável, tanto pela história, quanto por sua estética.

O filme japonês Ringu [O Chamado] é muito diferente. Retoma uma história clássica de fantasmas, mas utiliza uma tecnologia que não é clássica: o medo é provocado pela televisão e por uma fita de videocassete, que é bastante extraordinária. Um dia, a personagem do filme encontra, na sua sala, uma fita de videocassete sem saber como ela chegou até ali. Ao introduzi-la no videocassete e começar a passá-la, o telefone toca e, nesse momento, uma voz Ihe diz: "restam-Ihe apenas sete dias de vida, porque você viu este vídeo" ${ }^{\prime 7}$. Na primeira imagem do vídeo, distingue-se somente uma paisagem rural e, muito longe, uma espécie de poço. Mas, a cada vez que se vê o vídeo, a imagem se torna mais nítida e próxima. Pouco a pouco, a tampa do poço se levanta e algo sai de seu interior: um fantasma. Trata-se do fantasma de uma menina - isso se saberá mais tarde - que foi assassinada por seus próprios pais e que decidiu vingar-se e não esquecer jamais. Finalmente, esse fantasma sai do poço, e a personagem principal, que está vendo 
o vídeo, morre literalmente de medo. O espectador também não está longe de morrer de pânico devido a uma imagem muito simples: o fantasma se aproxima, inclina seus cabelos negros, muito longos e muito lisos à japonesa, que começam a sair pelo aparelho de televisão. Essa cena provoca um pânico monumental com recursos extremamente simples.

Passamos, agora, à segunda grande tendência do novo cinema fantástico: recentemente, veio à luz uma estranha aliança entre o cinema fantástico e a matemática, essencialmente, através de dois filmes, Cube de Vincenzo Natali, e Pi [Pi], como a letra grega $\Pi$, de Darren Aronofsky. O tema do sábio e da ciência não são, evidentemente, novos na literatura e no cinema fantásticos. Porém, não se trata aqui de retomar essa matemática, inclusive modernizando-a.

Em Pi, um jovem extremamente dotado para a matemática está convencido de que ela representa a linguagem do universo e que a natureza se expressa através de um conjunto de números, assumindo a imagem de desenhos matemáticos. Tenta, em vão, programando seu computador de modo cada vez mais complexo, encontrar a explicação e o sentido da vida e do universo em fórmulas matemáticas extraordinárias. Descodificar o mistério do universo graças à matemática se transforma em uma verdadeira obsessão para ele, que vive somente para isso, trancado em seu apartamento com uma volta dupla da chave, tendo, como única companhia, moças nova-iorquinas. A matemática se converte na própria essência da vida e em sua explicação. Algo que é bastante plausível cientificamente, embora a teoria do caos trate também de explicar as coisas por meio de conjuntos e desenhos matemáticos pouco demonstráveis. O filme se torna cada vez mais angustiante 
porque o herói, que encontra uma fórmula suscetivel de explicar tudo, põe, a cada instante, sua saúde mental em perigo, já que muita gente (o $\mathrm{FBI}$, a Bolsa, os religiosos, os especialistas da cabala) tenta apoderar-se de sua fórmula. A originalidade do filme não está tanto nos temas que apresenta: relação gênio/loucura, relação entre a matemática e a numerologia e entre o misticismo e a ciência, mas no papel desempenhado pela matemática, que constitui, ao mesmo tempo, a chave de todo um sistema perfeitamente fechado em si mesmo e uma prisão para o herói, que só tornará a ser um indivíduo quando perder seu dom para a matemática.

Em Cube, seis personagens acordam em um lugar estranho e terrorífico, formado por cubos encaixados uns dentro de outros, de onde parece impossível escapar. Como e por que chegaram ali? E, sobretudo, como sair desse lugar cheio de armadilhas horríveis? Cada cubo tem uma porta, no meio de uma de suas seis paredes, mas essa porta dá acesso a outro cubo! A decoração, muito high-tech, é notável e contribui para criar uma atmosfera de angústia e de surpreendente enclausuramento. Progressivamente, descobre-se que cada personagem possui um talento específico, e se pode pensar que a união de todas Ihes permitiria encontrar a saída da prisão. Porém, assistimos à desagregação do grupo e não à sua coesão. Nunca descobriremos a chave do enigma, nem o sentido dessa construção monstruosa. A única chave possível encontra-se nos números inteiros. Cada cubo tem, na parte inferior de cada porta, um número inteiro, ou melhor, uma série de números inteiros, e sua combinação poderia indicar onde se encontra a saída. A matemática também se converte, aqui, na única explicação possível para uma dada 
situação e o único caminho possível para a liberdade, e o mistério da matemática se superpõe ao mistério da história para formar um todo. O filme utiliza, com inteligência, ao mesmo tempo, nosso medo do confinamento e nossa fascinação pelo mundo da matemática e por sua abstração e irrealidade.

Nesses dois filmes, os números explicam e/ou representam o universo, assim como, em outros filmes, são utilizados para resgatar a imagem de uma realidade virtual. Por exemplo, em Matrix [Matrix], dos irmãos Andy e Larry Wachowsky", em que a "matriz" do título está representada na tela por cascatas de números.

A terceira tendência do cinema fantástico que desejaria apresentar se dá tanto no fantástico, quanto na ficção científica e diminui as fronteiras entre esses dois gêneros do imaginário: o jogo, as idas e vindas entre o real e a realidade virtual poderiam ser a expressão mais moderna da relação entre o real, o irreal, o surreal e os diferentes níveis de realidade que numerosas narrativas fantásticas apresentam. O sonho dentro do sonho e a interpenetração do sonho e da realidade são temas clássicos do fantástico, como no filme de Alberto Cavalcanti Au coeur de la nuit [ $\mathrm{Na}$ solidão da noite ${ }^{9}$, em que se dá o jogo dentro do jogo, a tal ponto que não se sabe se está no real ou no virtual, ou como em eXistenZ [eXistenZ], de David Cronenberg. Esses filmes apresentam semelhanças perturbadoras, e isso se acentua ainda mais já que Cronenberg se nega a usar recursos tecnológicos sofisticados, convertendo a relação real/virtual em algo orgânico.

8 Estes dois irmãos passaram pelo processo de mudança de gênero, ao longo desta segunda década do terceiro milênio, e, hoje, chamam-se Lilly e Lana Wachowski, respectivamente.

90 título original deste filme é Dead of Night, em inglês. 
Em Crash [Crash - Estranhos prazeres], igualmente realizado por Cronenberg, o corpo humano se transforma em metade carne/ metade prótese; em eXistenZ, alguém conecta sobre si mesmo - gamepod $^{10}$ metamorfoseando-se parcialmente para poder jogar eXistenZ. O filme é muito complexo e é muito difícil para as personagens, assim como para os espectadores, diferenciar o real do virtual, uma sensação que se acentua pela ausência de efeitos especiais delirantes ou de virtuosismo tecnológico. O mundo virtual é parecido, ponto a ponto, com o real e vice-versa.

Em Matrix, ao contrário, o real, igual ao virtual, tem uma existência demonstrada, mas ambos se diferenciam claramente, o virtual tendo como função oprimir e manter a escravidão inconsciente dos seres humanos. O mundo em que vivemos é virtual e nos faz crer que é o mundo real, enquanto que o verdadeiramente real é pavoroso, porque a Terra foi conquistada e destruída por uma invasão extraterrestre. Somente alguns que puderam resistir sabem o que aconteceu com o mundo real, e os humanos vivem na ilusão. Unicamente um messias poderia salvar a humanidade e garantir que o mundo tornasse a ser aceitável. Matrix é visualmente muito rico, e os efeitos especiais estão excepcionalmente utilizados, às vezes, por exemplo, nos combates de kung-fu, com uma beleza e uma intensidade surpreendentes, mas esse filme está longe de abrir caminho a uma reflexão filosófica como faz o de Cronenberg ou de alcançar a profundidade deste último [eXistenZ]. A força do filme está em sua capacidade de mostrar ao espectador visões imaginárias formidáveis, arrastando-o em uma espécie de turbilhão.

10 Trata-se de um dispositivo, que se conecta a um console de jogos, notebook, PC etc., para controlar videojogos. 
Esse filme suscitou diversas interpretações, inclusive de ordem filosófica, mas não creio que permaneça em nossa memória como The Sixth Sense ou existenz.

\section{UMA JANELA ENTREABERTA AO TERCEIRO MILÊNIO}

A partir dessa fascinação extraordinária do público pelos filmes fantásticos, pertençam ao campo do gore e da violência sangrenta, ao do horror psicológico e do suspense, mostrem um dilúvio de efeitos especiais ou, ao contrário, um chamado à imaginação do espectador ou à dimensão existência, é possível presumir o que poderia ser um novo cinema fantástico, o do terceiro milênio?

Pode-se pensar, sem grande risco de se equivocar, que os efeitos especiais irão aperfeiçoando-se e estarão cada vez mais presentes não só nas imagens de um filme, mas também na narração, até converterem-se em um dos elementos essenciais da narrativa, em detrimento da verdadeira intriga, das personagens e dos próprios atores. A escalada de efeitos especiais, apreciável nos últimos anos, compreensível no caso da ficção científica, poderia simplesmente "matar" o cinema fantástico. Inclusive Star Wars, Episode "I The Phantom Menace" [Guerra nas estrelas, Episódio I "A ameaça fantasma"], em que os efeitos especiais são perfeitos, conseguindo reproduzir, às vezes, a beleza surpreendente de uma cidade submarina, a magia dos primeiros episódios despareceu, e o mito criado por Georges Lucas se desgastou ${ }^{11}$. Isso se deve a que os efeitos especiais têm o enorme defeito de mostrar tudo sob

11 A afirmação de Irène Bessière antecede a produção e o lançamento em dezembro de 2015, pela Walt Disney Company, do Episódio VII de Guerra nas estrelas: O despertar da força (Star Wars: The Force Awakens), que promete continuação. Assim, ainda não se pode ter certeza do efetivo desgate que ela aponta. 
uma luz tal, que deixa pouco espaço ao sonho e à imaginação, ainda que possam suscitar uma sensação de encantamento. Alcança, por exemplo, The Haunting, o filme de Jan de Bont, que retoma o clássico tema da casa assombrada que é visitada por um pequeno grupo de jovens com o fim de descobrir seus segredos e cujo líder está interessado em estudar os mecanismos do medo. O filme é um festival de efeitos especiais e propõe uma decoração fabulosa para a casa que se transforma na verdadeira e única personagem da história, enquanto as outras personagens se tornam quase inexistentes. Nenhum efeito especial conseguirá fazer com que um filme medíocre seja um bom filme, nem provocar medo nos espectadores, porque o medo das personagens deixa de ser verossímil. Contudo, a suspension of disbelief é verdadeiramente importante no cinema fantástico. Bem diferente de The Haunting, a primeira versão dessa mesma história, dirigida por Robert Wise, destila medo e mistério durante todo o filme, apoiando-se em personagens muito bem delineadas e profundas, assim como em uma sólida intriga.

As novas tecnologias e os efeitos especiais poderiam, porém, trazer inovação e enriquecer o cinema fantástico, não tanto por sua utilização na filmagem (imagens numéricas), mas por sua capacidade ilimitada para mostrar visões e mundos imaginários, para oferecer uma estética particular a cada visão, a cada universo criado ou recriado, a cada filme que vai além de tudo o que pode ser imaginado até então, e por sua própria existência. Efetivamente, essas novas tecnologias podem gerar novos temas, como as relações entre o real e o virtual, cujos desdobramentos ficcionais e filosóficos são vertiginosos e infinitos, apresentando 
a questão da ilusão e da mentira, do simulacro, da inversão de nossa percepção (o virtual aparece com frequência muito mais real que o real), da manipulação dos indivíduos por um sistema que controla o acesso ao virtual, manifestação que poderia chegar a um verdadeiro totalitarismo. A evolução das novas tecnologias parece estar presa em uma espiral sem fim e dará, seguramente, nascimento a novas temáticas.

Da mesma forma, pode-se pensar que os grandes temas clássicos e universais perduraram, reatualizados segundo o gosto deste terceiro milênio: vampiros, monstros, homens divididos entre o humano e o animal, metamorfoses, mutações, cientistas e ciência etc., da mesma maneira que são retomados e reinterpretados, em cada época, os mitos gregos. Sem dúvida, a narrativa fantástica, cinematográfica ou literária, é a que mais se aproxima da fábula, inclusive do mito, desde que não ofereça uma explicação final racional e não negue o universo que lhe é próprio e, talvez, por essa razão, chegue a adquirir uma importância crescente.

Esse desejo, claramente evidenciado pelos espectadores deste fim e início de milênio, de uma experiência que cause terror e mistério, que levou o cinema fantástico a um verdadeiro renascimento indubitavelmente, não está alheia ao ingresso no novo milênio. Robert Sklar, professor da Universidade de Nova lorque e um dos mais reconhecidos historiadores do cinema, pensa que o cinema fantástico avança por ciclos sucessivos e conheceu sua maior popularidade nos períodos de graves tensões sociais (expressionismo alemão, idade de ouro do cinema de Hollywood contemporâneo da grande depressão econômica etc.) ou de decadência cultural. Hoje em dia, o mal-estar devido à chegada 
do terceiro milênio pode ser uma das causas do extraordinário êxito do cinema fantástico. Os sociólogos pensam que os medos imaginários fazem esquecer os medos concretos e os temores experimentados nas sociedades atuais. É possível, em todo caso, apreciar o desenvolvimento de duas tendências cinematográficas "góticas": o fantástico e a distopia - gênero que pertence ao campo da ficção científica e que descreve um porvir, um futuro "negro" -, ambas as tendências centradas ao redor do medo de hoje, o do presente ou o do futuro. Para concluir, expressemos simplesmente nosso desejo de que subsistam no futuro filmes fantásticos que, como The Sixth Sense, saibam apelar à imaginação e à inteligência do espectador e sugerir mais do que mostrar. 